\title{
Research on the Modern Material Purchasing and Management Mode under the Background of Informatization
}

\author{
Jiancheng Zhang \\ Material Supply Division Of Huabei Oilfield Company , \\ Renqiu ,Hebei Province 062552,China \\ Yu Zhang \\ Material Supply Division Of Huabei Oilfield \\ Company ,Renqiu ,Hebei Province \\ 062552, China \\ Jianjun Li \\ Material Supply Division Of Huabei Oilfield \\ Company ,Renqiu ,Hebei Province \\ 062552, China \\ Jian Xiao \\ Material Supply Division Of Huabei Oilfield \\ Company ,Renqiu ,Hebei Province \\ 062552, China \\ Lei Wang \\ Material Supply Division Of Huabei Oilfield \\ Company ,Renqiu ,Hebei Province \\ 062552, China
}

Abstract - In this paper, we conduct research on the modern material purchasing and the management mode under the background of informatization. Material is to maintain the normal operation of all kinds of resources integrated, the procurement is a significant means to ensure the enterprise supply as material purchasing is the purpose of the enterprise to obtain the value in the process of material in the production and business operation. Material purchasing constitutes the main part of enterprise cost, the success of the procurement is purchasing goods and materials to maximize value-added and it is directly related to the cost management of enterprises and the material purchasing, in order to further improve the enterprise's buyer need to constantly enhance their own professional level that actively explore a variety of procurement mode, different procurement methods to complete the procurement, to seek for more high-quality supplies for the enterprise, at the same time, improve the production and operation of the further enterprises benefits.

Keywords- Informatization, Management Mode, Modern Material, Purchasing and Management.

\section{Introduction}

The procurement as the largest industrial enterprises cost, its work efficiency and the effect to the enterprise integration of internal and the external resources, control the scale of investment, reduce production costs, maintain the security and stability of production and product quality control, has a significant impact. The supervision and management of state-owned enterprises materials purchase, must be based on general education, with a view to preventing and strengthen constraints, vigorously promotes investigating forming education, prevention, supervision with investigate the combination of the regulatory system [1-2].

Material management is the core of quality is the human factor, no material management personnel to master the sense of responsibility and quality consciousness, not high quality level of ideology and culture technology, would reduce the quality of material management. (1) Establish full care quality spirit of enterprise while strengthen the basis of quality of the material management work. Material management quality problem is not only a technical problem is also a 
question of understanding, only by executive order and simplicity of rewards and punishments is unsustainable, also must strengthen the education. (2) Integration research by the clustering analysis, the problems of the object system to reconstruct or specification management techniques and methods, to maximize the inheritance and development of scientific and practical technology of general material management. (3) Control plan management in essence belongs to the class management, is the control of the enterprise management activity, this kind of control is the control of the enterprise itself first, followed by supervision and auditing departments at the same level of control and control of the functional department [3].

As the key part of the cost control, the material purchase naturally become the focus of the modern enterprise management, construction of modern enterprise system also has the very big significance. However, the corresponding enterprises are facing with the listed challenges. (1) Enterprise for basic materials purchasing and supply that would have been unthinkable without a material management information system the modern enterprise material purchasing management cannot leave the auxiliary materials information management system. (2) From the perspective of the ideology of the enterprise material purchasing system, while there are still quite a number of enterprise's material management department functions, consciousness of quality center, production main idea, service consciousness also cannot adapt to the requirement of market economy. (3) Now some enterprises also implements the traditional multistage decentralized procurement management mode, enterprise most of secondary units from their local interests, main consideration is the production, supply, to use convenient, thus forming layers of a library, layer upon layer set, repeat reserves, not only wastes enterprise manpower and material resources, more serious is to increase the enterprise total inventory.

Focus on bulk purchase is not only the inevitable trend of the market economy development, and realize the general premise of lower purchasing price, it is in the procurement of multistage dispersion incomparable advantages as more and more enterprises.

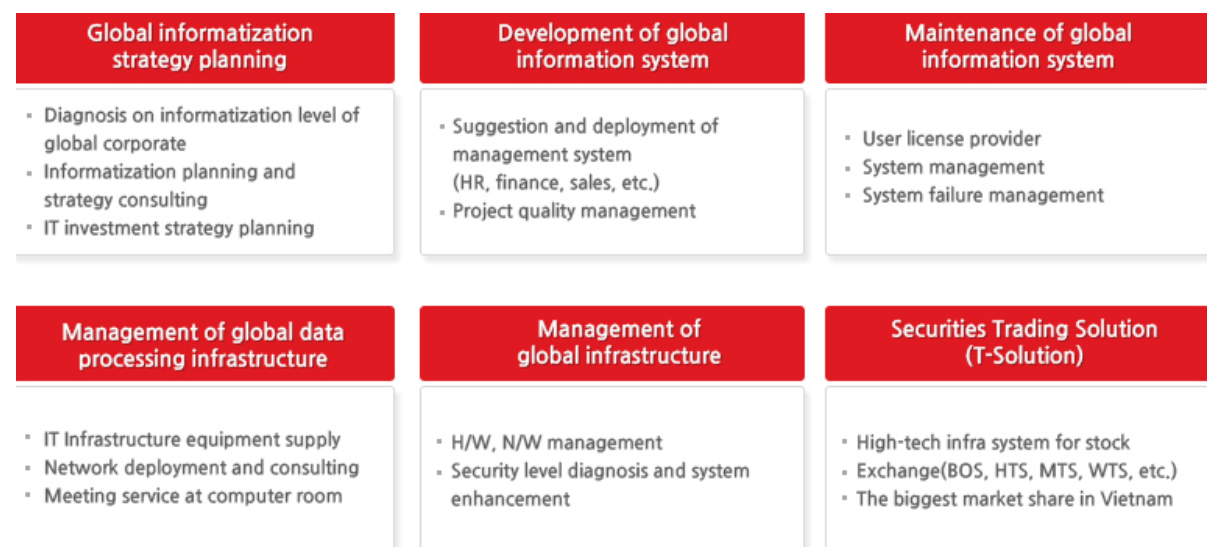

Figure 1. The Illustration of the Modern Material Purchasing and Management Mode

In this paper, we conduct research on the modern material purchasing and management mode under the background of informatization. Modern enterprise to establish a set of general strict procurement procedures and the scientific perfect match with other systems of the enterprises of the procurement management system, in order to pass the system of complete specification and working procedures of the effective control of the enterprise material purchasing process. 


\section{The Proposed Methodology}

The Management Information System. Generally can be divided into the management information system development method to process for the characteristics of the process oriented method and with the object of the system as the foothold of object-oriented method, in the process oriented approach is divided into life cycle method and prototype method using life cycle method for system analysis and design, from top to bottom is starting from global, general comprehensive planning analysis, and then designed and implemented step by step [4-5].

System consists of several interrelated things combined into the target with overall function and behavior of organic whole. Things or make up the system of the component is called system elements, each element permutation and combination to form a physical or logical relationship, some of these relationships is the statically stable, some are dynamic, constitute the system structure, the connection between the elements and make the system produces uniform function. The first is a system of general management information system, and have the system characteristics such as emergent properties, gradation that wants to use the system of ideas of management information system for comprehensive analysis. According to the degree of the scale of the development system and complex technology, the level of management, technical personnel's quality, and different factors such as the requirement of the development time, determine the management information system development method, ensure to smaller inputs to obtain the optimal effect and this has always been the concern of the management information system developers with the general and ordinary subject.

According to the literature survey, we could summarize the categories of the information system as the follows. (1) Due to the system target requirements for life cycle method, and the clear goal is often depends on the user, typically, user cannot define more exact input, process and output requirements. In this case, using the prototype may be the best choice. (2) Through the core general discussion of the management information system method, we made the analysis and comparison of various methods for the development of the common for developers to provide the basis of the selection method. (3) The establishment of the basic management information system can't start very perfect and advanced, that always go through a process of gradually improve, gradually developed. In fact, the management information system and other things as also have a life cycle. (4) Systems analysis stage decision goals and needs, its main task is to developers with users, starting from the initial requirements of the users, through detailed investigation and analysis of the current system and fully understand the new system.

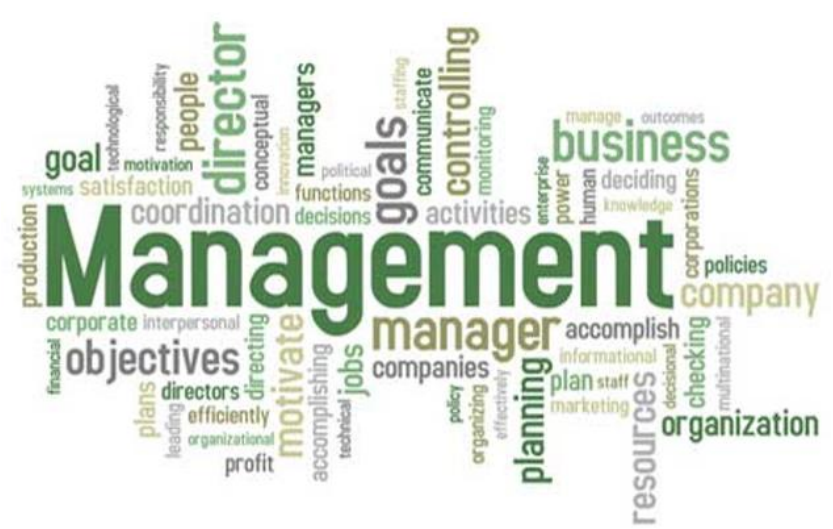

Figure 2. The Keywords of the Modern Management Patterns

\section{The Background of the Informatization.} The economic information system construction of our country has made great development, the logistics sector is facing new opportunities and challenges, logistics as a involves an important part of the input and output as plays an important role in enterprise management, and the importance of general logistics informationization is becoming more and more recognized by people. In today's under the new situation, to material management method is also put forward new requirements. Material 
management informationization is response and solutions. To strengthen the construction of informatization, the use of computer technology to implement material management information is an effective way to improve the level of material management that has the important practical significance [6].

Information barriers in the traditional material supply management is widespread, in the supplies of now still exist. Due to the constraints, the enterprise or the individual access to public information ability is limited, not the people, to achieve the comprehensive information such people, the guidance of the traditional logistics is the enterprise rely on this information is easy to cause the distortion of information and in the case of information technology is not developed, public information transfer and exchange range is not wide, update not in time, make more people to meet information barrier wall. With the high-speed development of the Internet and information technology changes with each passing day, is rapidly into the computer and the Internet. The rich diversity of online information and refresh in time, to make the information simple fast in a timely manner, with the Internet, information barriers clear effect is obvious. Therefore, the informalization procedures hold the following listed characteristics. (1) Many industry goods and core materials management information system is taking shape office automation system has been applied. In addition, the material management information system matching with the personnel labor management, equipment management, fuel management, financial management, the supplier management, and some other related information systems are also improved. (2) Under the environment of network information security problem is becoming more and more attention to, in terms of material management information construction, because often involve enterprise's business secrets, so that the material management information security issues are in the prominent position. (3) Current material management informationization construction achievement at the same time, we also cannot ignore the primary problems existing in the development of material management information. These problems restrict further improve the level of material management informatization, so that the companies need to focus on just one of the difficulties and solve [7-8].

The Enterprise Material Management. Material management work of the main process includes demand for production plan, material purchase to transport management, several links such as storage security and production application. Several links which is material from the supply market to the enterprise production process of production, consumption, so it can be said that the main function of basic material management is the enterprise production process in production supplies and the level of material management has a direct impact on production efficiency and level. So to strengthen the management and control of materials, reduce material waste and consumption, improve the efficiency of the use of materials that is to improve the production efficiency, the effective measures to reduce production cost. Generally speaking, in process of enterprise production management, management of the supplies mainly embodies in the management of a variety of means of production.

Due to the process of enterprise production is also the process of material consumption and thus formed in the product also requires a lot of material. In order to reduce the production cost of the products, as will have to be to effectively control the consumption of materials. This requires that the production department to strengthen improvement of production technology and perfect, continuous innovation and improve the level of production technology, in order to reduce material consumption, to achieve the goal of basic lower production cost. Constructing modern material supply management system can be achieved from the listed aspects. 
- The innovation service idea. To strengthen the service function, service work forward to the supplier's production process, to the material the use of the site, the material management in the longitudinal and horizontal extension, completed the development of service concept.

- Strengthen the consciousness of market. In real time to master a wide range of basic market information, seize the favorable opportunity in the process of material market change, for the enterprise to reduce costs, and create profit that is the enterprise supplies work prerequisite to improve business performance.

- Improve the management mechanism. The incentive-restricted mechanism that strengthens supervision of procurement and construction to establish perfect internal control management system is the enterprise to strengthen internal management, improve the competitive strength of the objective that is needed.

The Modern Material Purchasing. Supplies is a central link in chain of enterprise management, that is the third profit source of enterprises. Supply process including planning, a lot of link such as the supplier selection with the determination of purchasing price due to material supply work in the complicated and changeable social environment, affected by many factors, so there are different in the each link of risk. Supplies management information is the enterprise business activities in the process of the data collected, processed, diagnostic explanation, after general clear meaning, influence on the enterprise material management activities of the data. In the whole operation process of the materials enterprise, with the logistics of information transfer process, known as information flow, information flow is in order to achieve the planning, statistics, monitoring, dispensing, and the other functions of management. Information flow on the one hand, the logistics with the system, on the other hand can lead the logistics as a regular business exercise.

To reduce the purchase cost, the key is to strengthen the management of procurement staff. Under the condition of market economy we must train and bring up batch of familiar with the law of modern purchasing management, professional talents with pioneering spirit, has the consistent principle, and perfect talent incentive mechanism. In basic market research, price floating rate is difficult to grasp, telephone counseling is a kind of price, the negotiation with suppliers is a kind of price, instant money goods and futures trading is a kind of the price. Grasp the market to establish information network and optimizing the price in the market information, it is the system engineering.

Enterprises should in order to reduce the purchasing cost as foothold, selecting supplier gives full play to the role of creative procurement. Pay attention to the main supplier and strategic cooperation, while concentrating on the main suppliers. The logistics unobstructed enhance the market share to establish collaboration system. According to market demand adjust configuration plan, on the basis of business information, seize the opportunity for price adjustment, ingenious use of basic time, the price differential, timely adjust the configuration plan, and use the planning, the delivery and the settlement difference to take flexible settlement way for optimizing operation and effect.

\section{Conclusion}

In this paper, we conduct research on the modern material purchasing and management mode under the background of informatization. In the modern enterprise, the procurement occupies an important position. It is not only relation with enterprise production can smoothly, more relationship of the size of the profits. However, due to various reasons, the current enterprise procurement is more or less has certain problem, in order to prevent the occurrence of these risks, 
with smooth and healthy for general procurement, modern enterprises must strengthen the audit for procurement. The diversification of the procurement channels and price may be floating, that it is necessary to establish an incentive and price for purchasing price assessment information management network. Establish purchasing price assessment incentives and price information management network, are not only good for supervision, strict material purchasing link to promote the health work of procurement, and is beneficial to reduce procurement costs and increase enterprise economic benefits.

\section{Reference}

[1] Zhang, Meng, and Jinchuan Cui. "A quantitative description of complex adaptive system: The self-adaptive mechanism of the material purchasing management system towards the changing environment." Journal of Systems Science and Complexity 29.1 (2016): 151-170.

[2] Baker, Michael J., and Stephen T. Parkinson. Organizational buying behaviour: purchasing and marketing management implications. Springer, 2016.

[3] Birou, Laura, Heather Lutz, and George A. Zsidisin. "Current state of the art and science: a survey of purchasing and supply management courses and teaching approaches." International Journal of
Procurement Management 9.1 (2016): 71-85.

[4] Rostamzadeh, Reza, et al. "Application of fuzzy VIKOR for evaluation of green supply chain management practices." Ecological Indicators 49 (2015): 188-203.

[5] Singh, Amol. "A goal programming approach for supplier evaluation and demand allocation among suppliers." International Journal of Integrated Supply Management 10.1 (2016): 38-62.

[6] Groote Schaarsberg, M. Interactive operational decision making: Purchasing situations \& mutual liability problems. No. d3446205-1799-43a4-85f6-526a3dc4c7a3.

Tilburg University, School of Economics and Management, 2014.

[7] Golicic, Susan L., and Carlo D. Smith. "A meta - analysis of environmentally sustainable supply chain management practices and firm performance." Journal of Supply Chain Management 49.2 (2013): 78-95.

[8] Narasimhan, Ram, and Tobias Schoenherr. "The effects of integrated supply management practices and environmental management practices on relative competitive quality advantage." International Journal of Production Research 50.4 (2012): 1185-1201. 